\title{
La reforma laboral y sus fundamentos económicos en perspectiva histórica
}

\author{
Recibido: 7 de abril de 2020 • Aprobado: 27 de agosto de 2020 \\ https://doi.org/10.22395/ojum.v20n42a9
}

\author{
Ianina Harari \\ CEIL-Conicet, Buenos Aires, Argentina \\ ianinaharari@yahoo.com.ar \\ https://orcid.org/0000-0002-1877-0543 \\ Damián Bil \\ CEUR-Conicet, Buenos Aires, Argentina \\ damibil@gmail.com \\ https://orcid.org/0000-0002-7054-2927
}

\section{RESUMEN}

Este trabajo se propone analizar los fundamentos económicos que motivaron la presentación de un nuevo proyecto de reforma laboral durante el gobierno de Mauricio Macri en Argentina. Para ello adoptaremos una perspectiva histórica mediante la reconstrucción de las transformaciones que ha sufrido la legislación laboral, específicamente la ley de contrato de trabajo, que es la que rige la casi totalidad de los acuerdos laborales. También abordamos la evolución de las relaciones laborales en las últimas décadas y los intentos por parte del empresariado argentino de conseguir condiciones más favorables para un uso flexible de la fuerza de trabajo. Nuestro análisis muestra que la reforma laboral es parte de una estrategia de mediano plazo cuyo objetivo es mejorar las condiciones de acumulación de capital en Argentina, incluyendo un aumento de la explotación de la fuerza de trabajo. La metodología utilizada no solo se basará en el análisis cualitativo de las fuentes legislativas, sino también en análisis cuantitativos de información estadística nacional y mundial. Nos remitimos a diversos tipos de fuentes: legislación laboral, convenios y acuerdos de diferentes períodos históricos, series estadísticas oficiales nacionales e internacionales y aportes de otros autores.

Palabras clave: reforma laboral; relaciones de trabajo; legislación laboral; condiciones de trabajo; costos laborales; Argentina; macrismo; flexibilidad laboral; clase obrera; industria; competitividad. 


\section{Labor Reform and its Economic Foundations in a Historical Perspective}

\section{ABSTRACT}

This Works analyzes the economic foundation that motivated the presentation of a new Project of labor reform during the government of Argentinean President Mauricio Macri. For that, the article employs a historical perspective through the reconstruction of the transformations suffered by the labor legislation, specifically by the working contract law, which is the one that rules almost all of the labor agreement. The article also tackles the evolution of the labor relationships in the last decade and the initiatives of Argentinean entrepreneurship of achieving more favorable conditions for more flexible use of the workforce. The analysis shows that the labor reform is part of a mid-term strategy for improving the conditions for capital accumulation in Argentina, including an increase in the exploitation of the workforce. The methodology employed is based not only on the qualitative analysis of the legislation sources but also quantitative analysis of the national and worldwide statistical information. Several types of sources are used for that, such as labor legislation, agreements and covenants of different historical periods, national and international statistic series, and contributions made by other authors.

Keywords: labor reform; work relationships; labor legislation; work conditions; labor costs; Argentina; macrism; labor flexibility; working-class; industry; competitiveness. 


\section{INTRODUCCIÓN}

Este artículo es el resultado de la investigación que los autores desarrollan en el campo de la economía y la sociología laboral, que incluye el análisis de la legislación, sus fundamentos socioeconómicos y sus antecedentes históricos.

Durante el gobierno de Mauricio Macri (2015-2019), en la Argentina se ha instalado el debate sobre la reforma laboral a partir del proyecto que el Poder Ejecutivo presentó en el Congreso nacional, pero que nunca llegó a tratarse. El mismo había sido presentado para reestructurar las reglas de juego y recomponer las condiciones de acumulación de capital. El problema de los costos laborales argentinos fue puesto en la agenda pública a modo de instalar la necesidad de "modernizar" la legislación laboral vigente en el país.

En el mundo empresario, el anuncio original generó más apoyos (Do Rosario, 2017). De hecho, la UIA, en la voz de su titular Miguel Acevedo, salió a respaldar la reforma y señaló elementos menores a revisar, como la necesidad de que el acuerdo fuera con el apoyo de los sindicatos. Por su parte, otros sectores, en especial ligados a la producción agropecuaria, criticaron el proyecto por cierta tibieza en las reformas y lamentaron que no vaya más a fondo con ciertos elementos para reducir los costos laborales. Aun con estas observaciones, el anuncio cosechó ciertas esperanzas en el arco patronal. Esto se debe a que, en lo fundamental, es una medida de carácter industrialista. O sea, busca reestructurar el mercado laboral para generar mejores condiciones de acumulación y, con ello, la mentada afluencia de inversiones que esperaba el gobierno. En ese sentido, consideramos que la caracterización de la administración de Cambiemos como un gobierno neoliberal o antindustrial es errada (Zicari, 2016; Katz, 2017; Montes Cato y Ventrici, 2017). Más bien consideramos que las políticas económicas del gobierno de Cambiemos pueden encuadrarse en la corriente desarrollista (Sanz Cerbino et al., 2018). De la misma manera consideramos errada la asociación entre reforma laboral y gobiernos llamados "neoliberales" (De la Garza Toledo, 2000), dado que los aspectos de las relaciones laborales asociados a la "flexibilidad" se encuentran presentes en gobiernos de distinta orientación (Kabat et al., 2014). Desde cierta perspectiva favorable a la llamada flexibilidad laboral, esta consiste en desregular el mercado laboral, eliminar las rigideces propias de la legislación proveniente de la época del llamado estado de bienestar porque estas serían la causa del desempleo y la informalidad (OECD, 2019; Banco Mundial, 1995). Esta perspectiva oculta el verdadero funcionamiento de la acumulación de capital. Consideramos que determinadas configuraciones de las relaciones laborales responden, por un lado, al carácter de "cooperación antagónica" entre capital y trabajo (De Palma, 1972; Sartelli, 2001) y, por otro, a las condiciones históricas específicas de cada país o región de disputa y lucha de la clase obrera por regimentar los términos de su explotación. En la actividad productiva, la fuerza de trabajo es un costo, por lo que el capital busca 
reducirlo ya sea en lo que respecta a su remuneración (incluyendo lo que el empresario abona en impuestos y otras cargas que no van directamente al salario) como en lo que respecta a la flexibilidad de su uso. En estas condiciones, destrabar las rigideces del mercado laboral (para el capital) y reducir los "gastos" en salarios es una medida que favorece a la burguesía, y en particular al industrial. Por ello, lo que busca esta reforma es generar condiciones para recomponer la inversión de capital como estrategia de la burguesía en su conjunto.

En este artículo analizamos los fundamentos económicos que motivaron la presentación del proyecto de reforma laboral en perspectiva histórica. Estudiando la evolución de las relaciones laborales en las últimas décadas, colocaremos la situación actual en el contexto de los intentos de largo plazo de la burguesía por conseguir condiciones más favorables para un uso flexible de la fuerza de trabajo. Con ello buscaremos probar nuestra hipótesis. Intentaremos demostrar cómo el proyecto de reforma en cuestión es parte de una estrategia de mediano plazo para mejorar las condiciones de acumulación de capital en Argentina. En especial, intentaremos demostrar que la búsqueda de una reforma laboral responde a la necesidad de la burguesía argentina de incrementar la tasa de explotación y que se trata de una estrategia de largo plazo, es decir, no se trata de un objetivo exclusivo de ciertos gobiernos, sino que atraviesa a todos los gobiernos. Nos remitimos a diversos tipos de fuentes: legislación, convenios y acuerdos laborales de diferentes períodos históricos, series estadísticas oficiales nacionales (Indec, Ministerio de Trabajo, y del BLS para una comparación con la situación de los Estados Unidos), junto a aportes de otros autores.

\section{REFORMA Y FLEXIBILIZACIÓN LABORAL EN LA HISTORIA ARGENTINA RECIENTE}

En la Argentina la legislación laboral tiene origen en 1933 con la Ley 11.729 que estipula la estabilidad del trabajo, indemnización ante el despido arbitrario, vacaciones pagas y aguinaldo para los trabajadores de comercio. En 1945 se amplía su cobertura por decreto a la mayoría de las actividades, pero los empleados domésticos, trabajadores públicos y obreros rurales, entre otros, quedarán por fuera de esta ley y se regularán por regímenes especiales. En 1974, se sanciona la Ley de Contrato de Trabajo (LCT), que mantiene los mismos problemas que la norma laboral previa en cuanto a las exclusiones de ciertas actividades. En 1976, el gobierno militar la reescribe y sanciona mediante la Ley 20.744. Esa es la ley que rige hasta el día de hoy las relaciones laborales, aunque con un elevado nivel de generalidad. Una de las características del sistema de regulaciones laborales en Argentina es su heterogeneidad, dado que a la LCT y los regímenes especiales se agregan convenios colectivos sectoriales (Levaggi, 2006). Aquí demostraremos que las sucesivas modificaciones que se introdujeron en la legislación condujeron a eliminar conquistas obreras al igual que lo que sucedió en el nivel de los convenios colectivos de trabajo (James, 1981; Marticorena, 2010; Kabat et al., 2014), incluso bajo los sucesivos gobiernos kirchneristas (2003-2015), en contraposición a lo 
que plantean ciertos trabajos que tienden a dejar de lado modificaciones sustantivas (Candal, 2014; Palomino y Trajtemberg, 2006).

El gobierno militar de Videla introdujo varias modificaciones (Decreto 2882/79 de 1979, Ley 22.311 de 1980). Aquí analizaremos las principales que nos permiten comprender en qué sentido fue modificándose esta ley. Un primer punto importante es respecto a la extinción del contrato de trabajo. Impuso un tope a las indemnizaciones mediante un tope al salario que se usa para calcularla: no podía ser mayor a tres salarios mínimos. Además, renovó el régimen especial del Fondo de Cese Laboral (Ley 22.250, 1980) que reemplaza a la indemnización para los obreros de la construcción que impuso la dictadura de Onganía, y que van a mantener todos los gobiernos. Este último es el antecedente de lo que quiere imponerse en el nuevo proyecto de reforma laboral. Se trata de una modalidad en la cual una fracción del salario del obrero es destinada mensualmente a un fondo que cobrará cuando se extinga el contrato de trabajo, y que es justificado por la naturaleza temporal de la actividad.

En cuanto a la jornada de trabajo, se imponen los turnos rotativos, lo que mantendrán todos los gobiernos posteriores. Además, inaugura la posibilidad de que cuando el trabajo se efectúe por equipos, la jornada de trabajo se extienda más allá de las ocho horas diarias, con un máximo de ciento cuarenta y cuatro horas cada tres semanas. Este es el primer antecedente de lo que luego se conocerá como flexibilidad horaria en la legislación. Sobre las horas extras, para el trabajo por equipos habilita la posibilidad de tomarse horas de descanso compensatorio en lugar de cobrar las extras. Esto constituye el antecedente de lo que será el banco de horas, que se mantuvo en todos los gobiernos posteriores.

El gobierno de Alfonsín no modificó la ley de contrato de trabajo. Solo dictó la Ley 23.472 (1987) que nunca entró en vigor porque no se reglamentó. Esta ley creaba un Fondo de Garantías de Créditos Laborales que implicaba un descuento sobre el salario con el fin de destinarlo al pago de indemnizaciones. Resultaba un intento de generalizar un régimen que reemplace la indemnización de modo similar al que rige en construcción.

Fue el gobierno que inauguró el nombre de "flexibilidad laboral" para referirse al ataque de las conquistas obreras, en pos del aumento de la tasa de explotación. Hizo varios cambios con la promesa de bajar la desocupación y el trabajo en negro. Los resultados no fueron los esperados y la década terminó con una alta desocupación y trabajo en negro (figura 1). Por caso, el desempleo, según la medida oficial, pasó de 2,5 a $7,5 \%$ (Ferreres, 2010). 


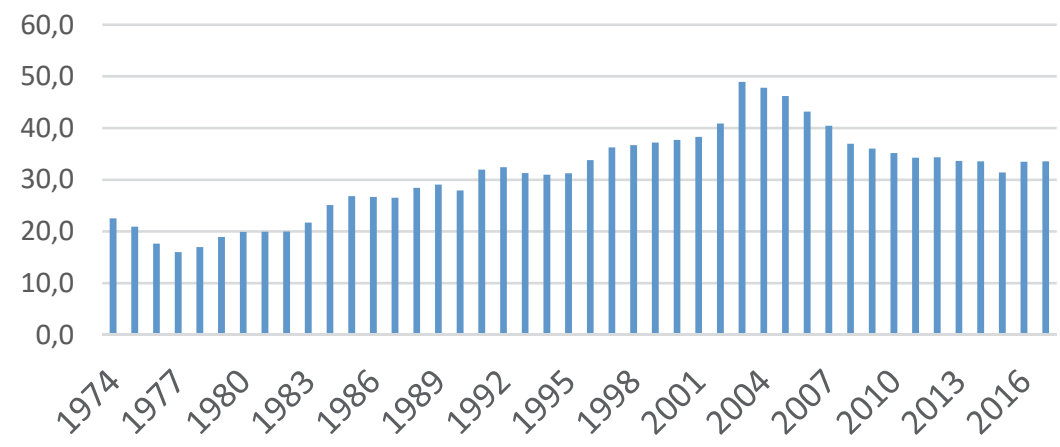

Figura 1. Evolución del empleo no registrado ("en negro"), Argentina, 1974-2016

Fuente: elaboración propia con base en Encuesta Permanente de Hogares (EPH) del Indec (1974-2016).

A partir de ese momento, se introdujeron nuevos cambios en la organización laboral. Veamos algunas de las principales modificaciones que se plasmaron en una serie de leyes (Ley 23.697/89, 1989; Ley 24.013/91, 1991; Ley 24.465/95, 1995; Ley 24.467/95, 1995; Ley 25.013/98, 1998). En principio se conformó todo un sistema de promoción del empleo en base a la reducción de aportes patronales y de incentivos al registro de personal. Se otorgó un plazo para regularizar a trabajadores en negro sin tener que pagar multas ni las contribuciones no abonadas. A las pymes (que concentran un $80 \%$ del trabajo y tienen mayor porcentaje de trabajo en negro) se les permitía desconocer los convenios colectivos del sector y negociar convenios propios, fragmentar las vacaciones, fraccionar el pago del aguinaldo y establecer un sistema de cuentas de capitalización individual en lugar de la indemnización.

En cuanto a la indemnización, se modificó la forma de calcular el tope del salario base (un promedio de las remuneraciones del convenio calculado por el Ministerio de Trabajo) e impuso un piso de dos salarios.

Respecto a las formas precarias de contratación laboral, se fomentó la tercerización y las modalidades de trabajo precarias y se impuso la responsabilidad solidaria. También se creó un sistema de pasantías y se introdujeron los tres meses de período de prueba, con posibilidad de extenderlo a seis por convenio, aunque después se lo redujo a treinta días.

También hubo novedades respecto a la negociación colectiva. Por un lado, se impulsó la descentralización de las negociaciones colectivas, lo que promovió los convenios por empresa, fragmentó y debilitó a los trabajadores en las paritarias. Además, se impulsó la renovación de convenios para incluir cláusulas de flexibilidad. Por otro lado, se prohibió la indexación salarial, es decir, que en los convenios se pueda poner una cláusula que permita el aumento automático del salario según la inflación (Altimir y Beccaria, 2000). 
Finalmente, impulsó un cambio en relación con la justicia laboral: al inaugurar el sistema de ART, creó las comisiones médicas para quienes opten por no ir a juicio.

El gobierno de De la Rúa (1999-2001) aprobó la reforma de una manera tan escandalosa, con acusaciones de sobornos (luego confirmados por el arrepentido Mario Pontaquarto) para aprobar el proyecto, que pasó a la historia como ley Banelco (Ley 25.250, 2000). Lo más importante de esa ley fue la extensión a tres meses del período de prueba, con posibilidad de que en los convenios se extienda a seis. Para las pymes este período era de seis meses, que podía estirarse a doce por convenio para trabajadores "calificados".

Bajo el gobierno de Néstor Kirchner (2003-2007) se derogó esta ley. Pero solo para volver a la reforma menemista, que no se anuló. Solo introdujo algunas modificaciones (Ley 25.877/04, 2004). Además, permitió mediante la homologación del Ministerio de Trabajo que muchos elementos de la flexibilidad se mantuvieran.

En relación con las indemnizaciones se mantuvo el tope indemnizatorio, pero se bajó el piso que impuso Menem de dos salarios a uno. En cuanto a la jornada de trabajo, mantuvo la posibilidad de pactar el banco de horas en acuerdos y los avaló desde el Ministerio de Trabajo. A su vez, permitió que las horas extras se compensaran con horas no trabajadas en lugar de pagarse el adicional.

Sobre las modalidades precarias de empleo, mantuvo en tres meses el período de prueba, y las formas de contrato por tiempo determinado se expandieron notablemente hasta alcanzar un $9 \%$ de los trabajadores en blanco. En el Estado este tipo de contratación pasó del 6 \% en 2003 al $19 \%$ en 2015.

En cuanto a la promoción del empleo y el blanqueo, se redujeron los aportes para el registro de trabajadores de pymes y grandes empresas. Permitió también la firma de convenios de corresponsabilidad gremial (Ley 26.940/14, 2014) que implicaba reducción de aportes patronales en todas las ramas. Estos convenios son acordados entre el sindicato y las asociaciones patronales, y permiten la sustitución de las cargas patronales normales por un mecanismo sui generis de pago diferido de una "tarifa sustitutiva", denominada así porque remplaza los aportes empresarios. La tarifa se negocia entre el sindicato y la cámara patronal de cada sector y se actualiza periódicamente. Se establece por la unidad de producción correspondiente a cada actividad, por ejemplo, tonelada o quintales, y se paga una vez terminado el ciclo productivo cuando el empresario vende su mercancía. Por tanto, se calcula en función de lo que produjo en la campaña de ese año con la posibilidad de abonarla en cuotas. Todo ello no logró bajar el empleo en negro en una magnitud significativa, sino que se mantuvo en un promedio relativamente estable. 


\section{EL PROYECTO DE MACRI}

El proyecto de reforma laboral del macrismo, que incluye una reforma a la LCT, contempla varios puntos. El mayor acuerdo que hay entre el Gobierno y la CGT es sobre el blanqueo laboral, que permitiría a la central sindical aumentar su base de afiliación y al gobierno la base de recaudación para la seguridad social (Anses). Sin embargo, el triunvirato cegetista no acordaba con los porcentajes que querían establecerse para las cargas patronales. Entonces, el Gobierno quitó la rebaja de las cargas patronales del nuevo proyecto y dejó ese apartado para incorporarlo a la reforma tributaria. Vale recordar que esta iniciativa ya había sido impulsada en los gobiernos de Menem y de Cristina Kirchner. En ese sentido, la expresidenta no solo rebajó las cargas empresarias para los trabajadores que registrasen las pymes, sino también para empresas más grandes, al margen de que buena parte del espectro pyme opera como tercerizado de las grandes. Otra novedad respecto al blanqueo es la eliminación de la indemnización que el empleador estaba obligado a pagar al trabajador no registrado cuando este lo intimaba a que lo registrara (Ley 24.013, 1991, arts. 8-10). En la práctica, esto le permitía al trabajador no registrado cobrar una indemnización en caso de despido. El Gobierno quiere eliminar esta posibilidad y reemplazarla por una multa de un valor bastante menor, que la patronal deberá pagarle a la Anses sin que el trabajador perciba un solo peso. Así, se desincentivan las denuncias por trabajo en negro.

Un cambio que se aplicó en Brasil y que se creía que iba a copiar Macri es la eliminación el principio de irrenunciabilidad (Ley 20.744, 1974, art 12). Esto significa que no puede pactarse la supresión o disminución de algún derecho establecido por la LCT, el convenio colectivo o estatuto profesional o contratos individuales. Esto quiero decir que la patronal no podía imponer condiciones a la baja con respecto a lo pactado previamente en cualquier nivel. La propuesta no es eliminar esto de forma completa, sino solo en relación con las condiciones firmadas en acuerdos individuales. En la nueva versión del proyecto, el Gobierno "suavizó" este cambio agregando que los cambios deberán ser homologados ante una autoridad de aplicación y que el trabajador deberá estar acompañado por un representante sindical.

En un sentido similar se buscará modificar la aplicación del criterio ius variandi o la facultad de modificar las formas y modalidades del trabajo por parte del empleador (Ley 20.744, 1974, art. 66). Hasta ahora, cuando la patronal modificaba unilateralmente alguna condición de trabajo en detrimento del obrero, este último tenía la posibilidad de exigir ante la Justicia que se restablecieran las condiciones previas o bien considerarse despedido. La modificación propuesta reemplaza la posibilidad de accionar judicialmente por el reclamo "ante la instancia que se contemple para ello en el convenio colectivo de trabajo aplicable" (De Diego, 2017). Este sería un paso más que se suma a la reforma de la ley de ART, en el ataque a la "industria del juicio". El Gobierno estaba dispuesto a negociar este punto desde un principio. Finalmente, la modificación 
será que se pueda accionar judicialmente, pero no por medio de un proceso sumarísimo porque perjudicaría al trabajador y dilataría los tiempos de resolución (y con ello los costes del proceso judicial).

Estos dos últimos ítems apuntan a reforzar la potestad de la patronal de degradar condiciones de trabajo con algo menos de restricciones, aunque de forma moderada. Hay otra serie de modificaciones que apuntan al ahorro de costos laborales de forma más directa (aunque todas las modificaciones van en ese sentido).

Uno de los cambios más importantes es el ataque a la indemnización por despido. Recordemos que la clase obrera argentina ha logrado que el costo del despido sea elevado respecto a otras partes del mundo. Como ya mencionamos, para los trabajadores en negro se quiere eliminar la indemnización que percibían al denunciar su situación que, en los hechos, era la forma que tenían de acceder al cobro de algún resarcimiento material por despido. Ahora bien, para los trabajadores en blanco se quiere reducir el cálculo de la indemnización (Ley 20.744, 1974, art. 245). Hasta ahora se calculaba un sueldo por año estimado sobre "la mejor remuneración mensual, normal y habitual devengada durante el último año". Como hasta ahora no se explicita qué ítems están incluidos y cuáles no, su interpretación permite la inclusión de todas las sumas que percibiera el trabajador. El Gobierno quiso excluir de la base salarial sobre la que se calcula las horas extras, el aguinaldo, las comisiones, premios o bonificaciones. En la modificación se quitan las horas extras y las comisiones y quedan en pie la exclusión del aguinaldo y las bonificaciones. En un principio, el Gobierno pretendía que el plazo para accionar judicialmente disminuyera a un año, pero en la nueva versión mantendría los dos años (Ley 20.744, 1974, art. 256).

Hay una modificación mayor respecto a las indemnizaciones: se permite la creación de fondos de cese laboral por sector, lo que copia el modelo que ya existe en la industria de la construcción desde 1967 (Decreto Ley 17.258, 1967) y que fue incorporado luego al estatuto de la actividad en 1980 (Ley 22.250, 1980) (Harari, 2019). Los obreros de la construcción hace décadas han perdido el derecho a cobrar una indemnización y, en lugar de ello, los patrones del sector simplemente depositan en una cuenta un porcentaje del salario que, acumulado mes a mes, será lo que el obrero se lleve cuando finalice la relación laboral. Esto está "justificado" en la naturaleza transitoria de la actividad. Ahora no hace falta ningún fundamento para implementar este régimen. El proyecto final establece que se discutirá su implementación en las negociaciones colectivas por sector, así como el porcentaje salarial destinado al fondo. Por supuesto que ello supondrá un gran ahorro para los empresarios a la hora de deshacerse de personal. La CGT podría quejarse de este punto, pero hay que recordar que este fondo será administrado por un instituto creado a tal fin, compuesto por el sindicato y la cámara patronal, que administrará los fondos y podrá disponer de ellos. Claramente, esto se constituirá como una nueva caja para la burocracia sindical. 
Hay un punto que el Gobierno quiere impulsar porque le permite a las patronales ahorrar el costo de las horas extras. Esto lo conseguiría mediante la implementación del banco de horas. Históricamente, una conquista del movimiento obrero argentino fue que la hora de trabajo por fuera de la jornada laboral debía abonarse un 50 \% más que la normal o un 100 \% más si fuera sábados después del mediodía, domingos o feriados (Ley 20.744, 1974, art. 201). Esto resulta un problema para amoldar la jornada laboral a los ciclos productivos y económicos. Una modalidad que se dio en la práctica, a través de actas acuerdo, fue la implementación del banco de horas. Mediante este sistema, los trabajadores cobran por la jornada completa en momentos de baja de la producción, aunque trabajen menos horas. Esas horas no trabajadas y cobradas deben ser devueltas en algún momento que la empresa lo necesite bajo la forma de horas extras sin cobrar. Esto quiere decir que la empresa adelantaba el pago de horas de trabajo que luego el trabajador debe devolver, pero sin recibir el plus que corresponde por hora extra. Esta modalidad existe hace tiempo y fue moneda corriente durante el kirchnerismo, por ejemplo, en la industria automotriz. En la práctica esto permite la eliminación del plus por hora extra. La modalidad es bastante parecida a la forma de contabilizar la jornada laboral de manera más bien anualizada que rige en Francia. El Gobierno quería que el banco de horas se incorporara a la LCT, pero va a promover que se negocie por medio de los convenios colectivos, lo que lleva a que se discuta sector por sector.

Hay otro tipo de reformas que apuntan a favorecer la tercerización laboral bajo diferentes modalidades. La tercerización, ya sea contratando empresas para tareas específicas o monotributistas, permite contar con trabajadores en peores condiciones que los trabajadores de planta. Hay toda una serie de modalidades que le permiten a una empresa deshacerse del problema de contratar una parte de su fuerza laboral con todos los costos que implica el contrato de trabajo por tiempo indeterminado, registrado y bajo convenio colectivo. Por supuesto, se trata de situaciones que ya fueron habilitadas por el menemismo y que el kirchnerismo mantuvo y expandió. Lo que busca ahora Macri es profundizar esta situación. Por un lado, quiere excluir de la responsabilidad solidaria una serie de actividades (Ley 20.744, 1974, art. 30). Hasta ahora, la empresa principal era responsable por las condiciones laborales del personal de la empresa que subcontratara y cualquier tercerizado podía accionar judicialmente con ella. El Gobierno quiere que esto no se aplique para las principales actividades que suelen ser tercerizadas (limpieza, mantenimiento, gastronomía, informática), entre las que se incluían los servicios de transporte, lo que ofuscó a Hugo Moyano. No obstante, el ministro Triacca aceptó agregar que se trataría solo de transporte de pasajeros, lo que excluiría la actividad de camioneros. También se quitó de la excepción a los servicios informáticos, área en la cual se conformó hace poco un sindicato ligado a Facundo Moyano. Además, en el nuevo proyecto se agregó que la empresa deberá informar al sindicato de las subcontrataciones que quiera hacer, tendrá treinta días para exhibir los comprobantes cuando lo requiera 
la autoridad de control o el trabajador y se eximirá de la responsabilidad solidaria a las empresas que cumplan con los requisitos de control sobre la tercerizada, lo que va a dificultar la acción judicial contra la empresa principal. Esto último es algo que solicitaban sectores como el automotriz buscando replicar una situación que ya se produce en Brasil.

Por otro lado, el Gobierno pretende avanzar en la formalización de la contratación "trabajadores autónomos" para evitar demandas por fraude laboral. Así, se excluye del ámbito de aplicación de la LCT (Ley 20.744, 1974, art. 2) a los trabajadores autónomos "económicamente vinculados", que se referiría a quienes "presten servicios" de manera habitual y directa para una persona o empresa de la que dependan económicamente hasta el 80 \% de sus ingresos anuales y no supere las veintidós horas semanales de trabajo. El acuerdo con la CGT incluyó el agregado de que estos trabajadores se regirán por una regulación estatutaria especial. En un principio el Gobierno quería excluir de la LCT también a los trabajadores independientes y "a sus trabajadores independientes colaboradores", un eufemismo para referirse a un intermediario o subcontratista, para quien se iba a habilitar un régimen de aportes simplificado. Finalmente, esta figura fue eliminada y se prevé la conformación de una comisión tripartita para elaborar un régimen especial. Asimismo, se institucionaliza la figura del pasante bajo la noción de prácticas formativas (hasta de un año y medio), con la que se puede trabajar un máximo de treinta horas semanales, aunque con posibilidad de añadir diez más. Se les abonará una suma no remunerativa como "estímulo".

Por supuesto que todas estas modificaciones vienen junto con otras que actúan como un cebo. Por ejemplo, la extensión de la licencia por paternidad y la posibilidad de tener jornada de trabajo reducida por el cuidado de los hijos.

En el balance, estas medidas implican una degradación de las condiciones laborales y de vida de los trabajadores argentinos. Se precariza la contratación, el desempeño y aún el despido, mientras que se legaliza el avance de la tercerización, entre otras. En ese punto, parece claro que el gobierno busca un mercado laboral más parecido al de los principales competidores regionales, como Brasil o México, donde los costos laborales para el empleador son mucho menores (tabla 1).

Tabla 1. Costos por despidos según antigüedad en semanas de sueldo.

Argentina, Brasil y Estados Unidos (2017)

\begin{tabular}{lccc}
\hline Indemnizaciones por despido & Argentina & Brasil (Sao Paulo) & Estados Unidos (Nueva York) \\
\hline Con un año antigüedad & 4,3 & 1,7 & 0 \\
Con cinco años antigüedad & 21,7 & 8,3 & 0 \\
Con diez años antigüedad & 43,3 & 16,6 & 0 \\
Promedio & 23,1 & 8,9 & 0 \\
\hline
\end{tabular}

Fuente: elaboración propia con base en Doing Business Database, World Bank (2017). 
Mientras los aportes patronales en Argentina representan un $40 \%$ de lo desembolsado por el empresario, en Brasil ese porcentaje es del $30 \%$ y en México del $19 \%$. En Brasil tampoco se cuenta con obras sociales sindicales, lo que obliga a los trabajadores a optar por medicina privada o el sistema público, totalmente colapsado. Lo más importante es que Argentina tiene un costo de despido elevado, como indica la tabla 1, tres o cuatro veces superior al brasileño; mientras que en los Estados Unidos esta acción no tiene costo para el empleador.

En ese sentido, cabe señalar que Brasil ya puso manos a la obra con una reforma que, entre otras cosas, habilita la extensión de la jornada a doce horas, reduce el período de descanso, permite fraccionar vacaciones, establece de banco de horas, amplía la figura de "autónomo" para desligar de responsabilidades al patrón, terceriza tareas incluso en la actividad principal de los establecimientos, flexibiliza más las condiciones de despidos, reduce las indemnizaciones, dificulta el acceso a la justicia laboral, entre otros. Como se ve, una receta muy similar a la que quiere meter el Gobierno en Argentina.

\section{LOS MOTIVOS ECONÓMICOS DE LA REFORMA LABORAL}

La razón por la que el Gobierno y la burguesía quieren avanzar con esta reforma es sencilla. No responde a una política revanchista, neoliberal, ni nada por el estilo. Como observamos es la política que siguen, con distinta intensidad, los gobiernos burgueses desde hace tiempo. El motivo de fondo, como en Brasil, responde al intento de reorganizar la estructura laboral para facilitar la fluidez de tránsito en el mercado de trabajo. En ese punto, los propios organismos de la burguesía a nivel internacional señalan las dificultades. El Foro Económico Mundial (Schwab, 2017), en su informe anual de competitividad, indica que la Argentina avanzó del lugar 104 al 92 (entre 137 países) en el ranking general. Ahora bien, en materia laboral, se mantiene entre las últimas posiciones. Entre los renglones principales, según el organismo fundado por Klaus Schwab, la Argentina se ubica en el puesto 132 sobre 137 países en "eficiencia del mercado laboral". En sub rubros de ese apartado, la pobre performance se refleja en la poca flexibilidad para determinar salarios (puesto 133), las rígidas prácticas de contratación y de despido (135), los efectos de los impuestos en el incentivo a la contratación y al trabajo (134) y la deficitaria relación entre la paga y la productividad (114). La capacidad de retener talentos en el país es el único renglón en el cual la Argentina se encuentra entre la primera mitad de países encuestados (48) (Schwab, 2017).

Las "regulaciones restrictivas" a nivel laboral ocupan el quinto puesto entre las preocupaciones de los inversores, luego de la inflación, los impuestos, la inestabilidad política y las dificultades de financiamiento. Por encima de la burocracia estatal, se encuentra la corrupción, los déficits de infraestructura o la "poca ética" de trabajo. Esta evaluación no es anecdótica, puesto que da cuenta de la caracterización 
que hace del mercado de trabajo local la burguesía internacional, a la cual el macrismo busca seducir para desatar la mentada lluvia de inversiones.

Más allá de lo que señalen los órganos del capital más concentrado, conviene analizar lo que ocurre a nivel estructural. Luego de la crisis de 2001 y de la salida de Lavagna, que implicó el pasaje de un peso sobrevaluado en casi $80 \%$ a una subvaluación del $25 \%$, la industria manufacturera comenzó una recuperación basada en la protección de hecho brindada por un dólar caro que limitaba el ingreso de productos importados, pero sobre todo por la drástica caída del salario y con ello del costo laboral, como puede observarse en la figura 2.

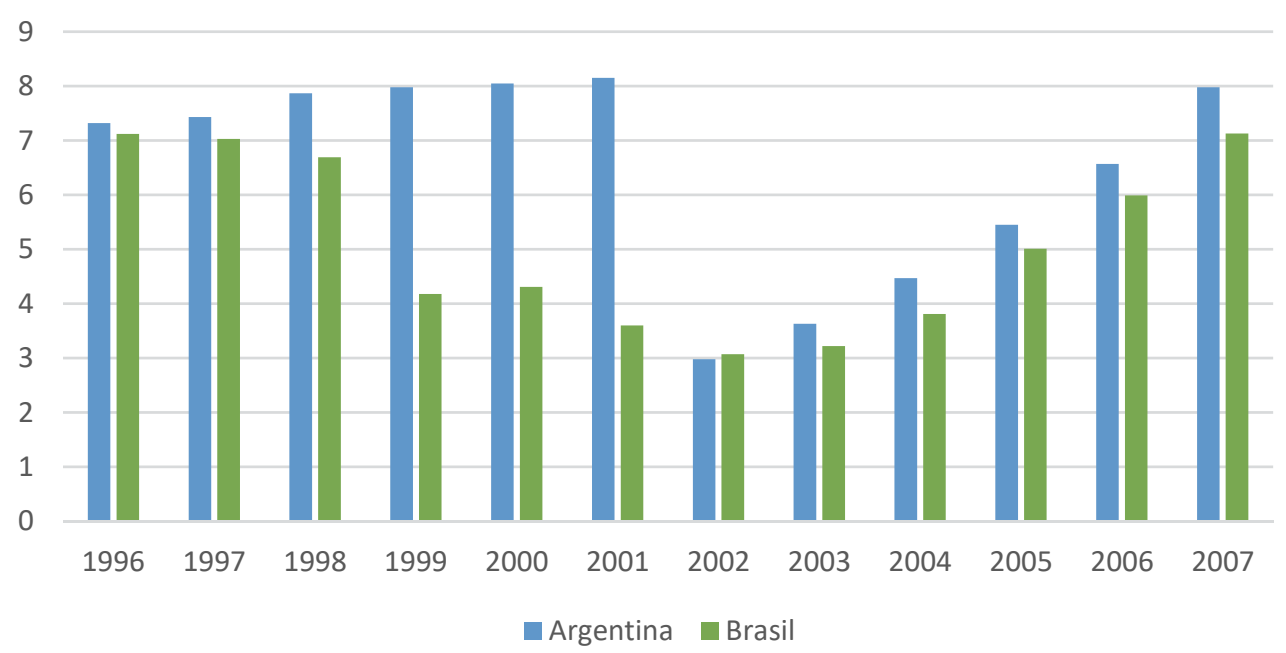

Figura 2. Costo laboral por hora para todo empleo en la manufactura, en dólares según tipo de cambio nominal, por hora, Argentina y Brasil, 1996-2007

Fuente: elaboración propia con base en datos de Foreign Labor Statistics, U.S. Bureau of Labor Statistics (2007).

Esto quiere decir que, con la crisis de 2001-02, el costo laboral en la industria manufacturera argentina como muestra la figura 3 se redujo un $173 \%$ en promedio, con algunas ramas más afectadas, como la industria del cuero y del papel. 


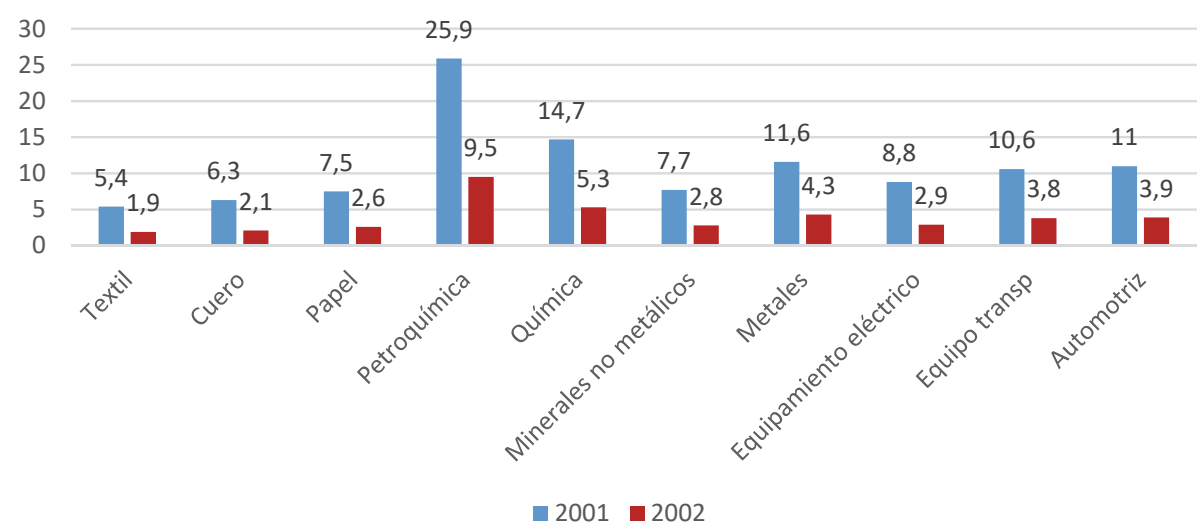

Figura 3. Costo laboral por hora por sectores seleccionados en la industria manufacturera argentina, dólares corrientes por hora, 2001 y 2002

Fuente: elaboración propia con base en datos de Foreign Labor Statistics, U.S. Bureau of Labor Statistics (2007).

La crisis económica, entonces, desplomó el costo laboral (y el salario de bolsillo) de los trabajadores argentinos. Esta caída de las condiciones de vida de la clase obrera fue uno de los puntales que permitió el "rebote" y la recuperación posterior de los indicadores del sector. Sobre las espaldas de la capacidad instalada previa, la industria inició un ciclo de ascenso en su actividad. Pasó de una capacidad utilizada general del 55,7 \% en 2002 a 78,7 \% en 2011 (figura 4). Entre los sectores beneficiados con ese proceso, se encontraron la edición e impresión, refinación de petróleo, química, productos de caucho y plástico, minerales no metálicos, la automotriz y la metalmecánica.

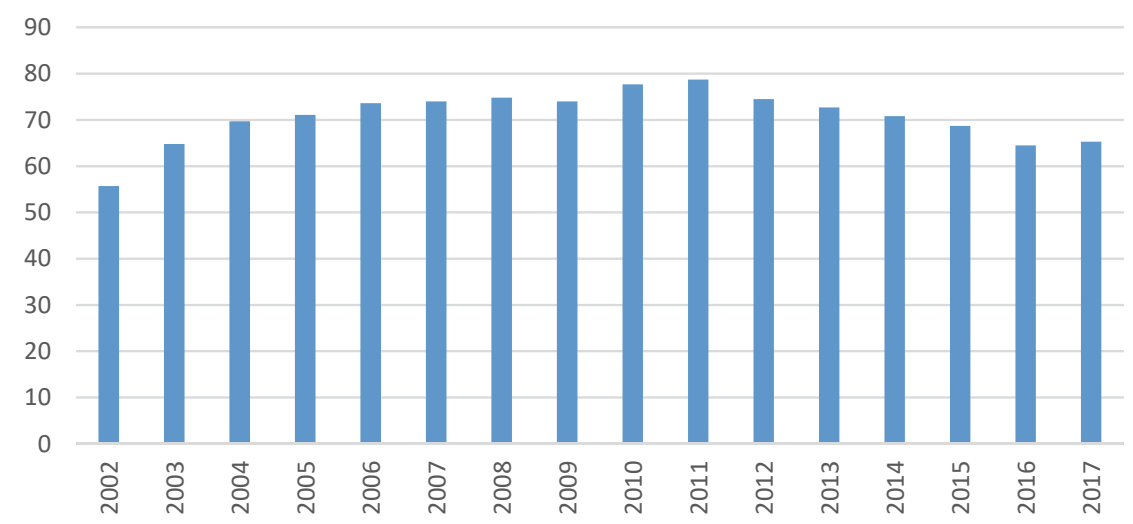

Figura 4. Capacidad instalada utilizada en la industria manufacturera argentina (en porcentajes), 2002-2017

Fuente: elaboración propia con base en Utilización de la capacidad instalada en la industria, Indec (varios años). 
Asimismo se expandió la escala productiva en sectores concentrados entre el 7 y el 20 \%: la automotriz pasó de una capacidad instalada teórica de producción de 726.000 vehículos en 2004 a 1.159.000 en 2014; los productos del papel, de 1,8 millones de toneladas de capacidad a 2,2 en el mismo período; mientras que en siderurgia y metales básicos de dieciséis millones de toneladas al año en 2004 a casi veintiún millones para 2013 (figura 5).

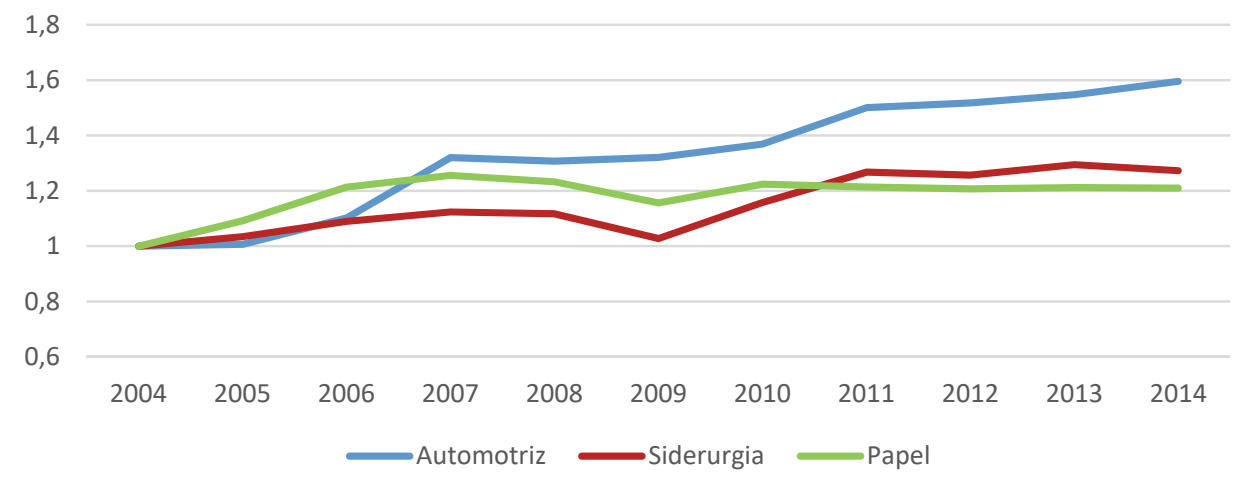

Figura 5. Capacidad de producción teórica en ramas manufactureras seleccionadas, Argentina, 2004-2014 (base $2004=1$ )

Fuente: elaboración propia con base en datos de Estadística de Productos Industriales y de Utilización de la capacidad instalada en la industria, Indec (2017).

Nota metodológica: calculamos este indicador a partir de ponderar la producción de cada sector, informada en la Estadística de productos industriales de Indec (2017), con la capacidad utilizada por cada rama en el año en cuestión.

El valor bruto de producción de la industria manufacturera, en términos reales, se incrementó en el período 2004-2011 en un 45 \% (figura 6). No obstante, a partir de 2012 comenzó a decrecer en consonancia con la disminución del volumen físico de fabricación en varias actividades, como, por ejemplo, la industria automotriz. 


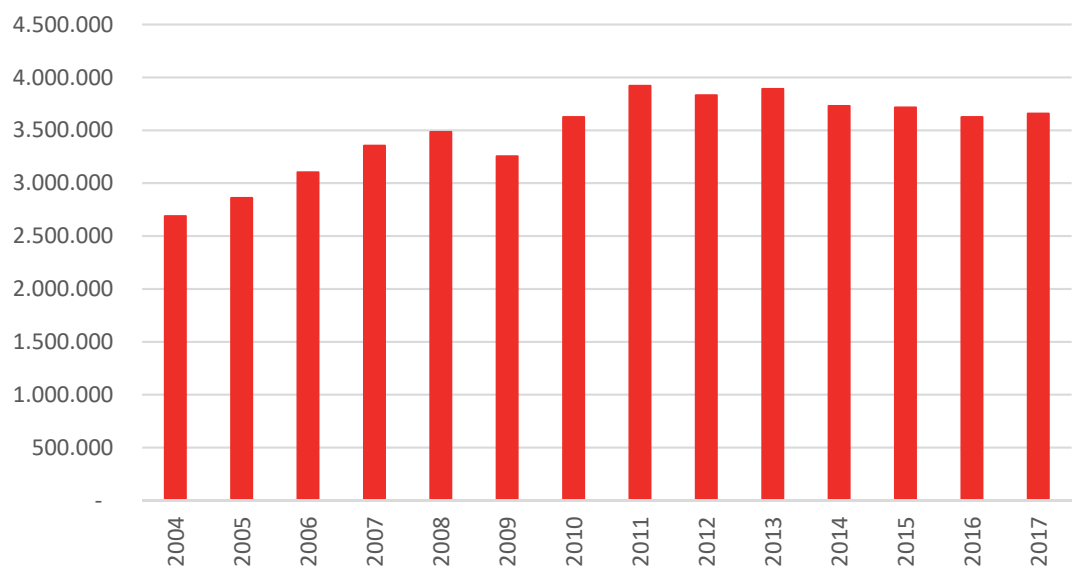

Figura 6. Valor bruto de producción de la industria manufacturera en Argentina, en millones de pesos del año 2016, 2004-2017

Fuente: elaboración propia con base en Agregados Macroeconómicos, Cuentas Nacionales, Indec (2020).

Aun así, la productividad laboral se incrementó en ciertas ramas. Hay algunos indicadores indirectos que permiten acercarnos a esa conclusión. Uno de ellos es el valor bruto de producción (VBP) por ocupado (figura 7), que mostró diferente comportamiento según el sector.

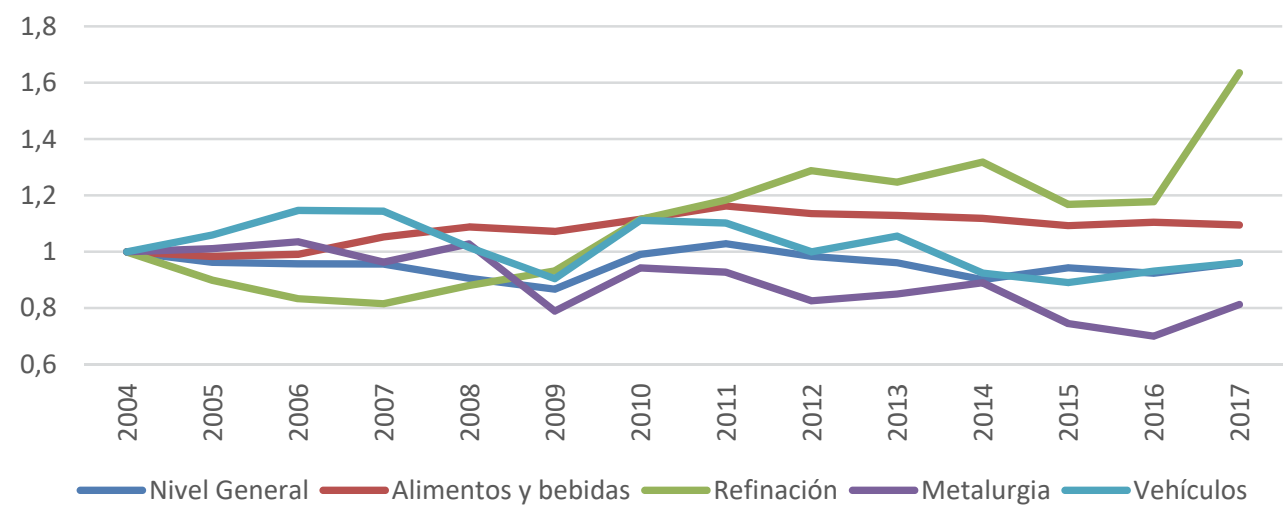

Figura 7. Evolución del valor bruto de producción por ocupado, nivel general y ramas seleccionadas, 2004-2017 (base $2004=1$ )

Fuente: elaboración propia con base a Agregados Macroeconómicos, Cuentas Nacionales, Indec (2020) y

Boletín de Empleo Registrado. Serie anual, Observatorio de Empleo y Dinámica Empresarial (2017). 
Si bien ciertas ramas sufrieron una retracción en el VBP por trabajador registrado, producto probablemente de una caída aguda de los niveles productivos (por caso, la industria del cuero), en términos generales de 2004 a 2013 este indicador mostró un leve incremento. Este índice tiene la dificultad de medir magnitudes de valor que se modifican por efectos diversos. Una medida más precisa puede ser la productividad en unidades físicas de producto. Contamos con la posibilidad de realizar aproximaciones para ramas particulares, como la industria automotriz. El aumento de la productividad laboral aquí puede observarse en indicadores indirectos, como el de horas trabajadas por unidades de producto (figura 8). En esta rama, según Adefa (2018), en 2004 se insumieron setenta y cuatro horas por vehículo fabricado. En 2013, las horas por unidad habían bajado a cincuenta y uno.

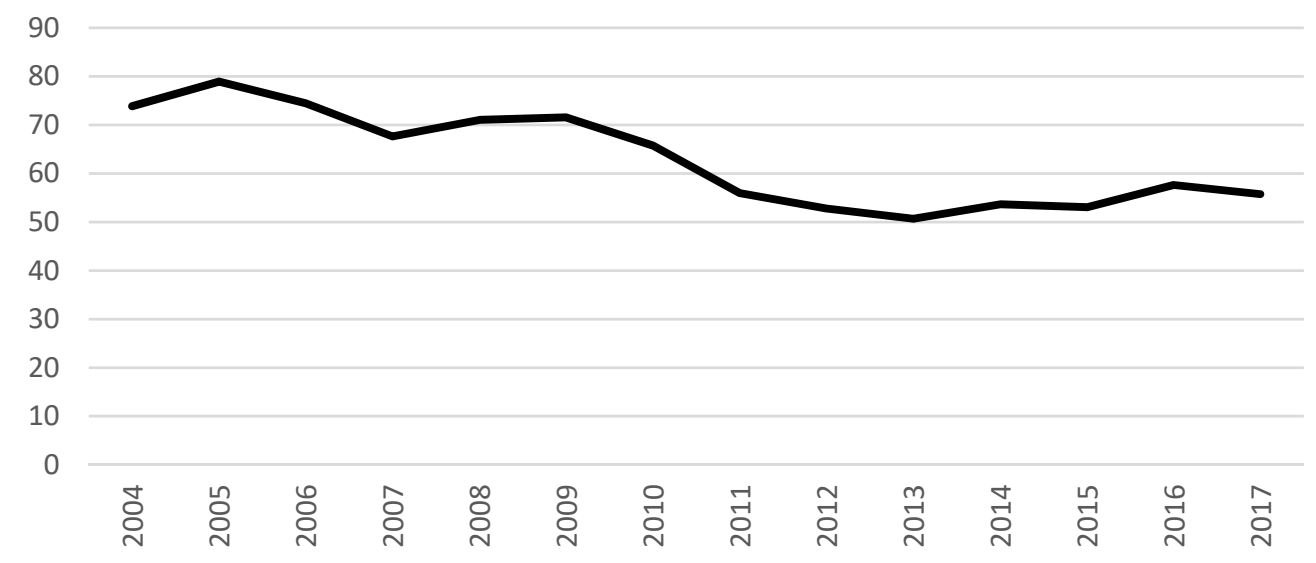

Figura 8. Horas trabajadas por vehículo en la industria automotriz argentina, 2004-2017

Fuente: elaboración propia con base en datos de Anuario. Datos Básicos, Adefa (2018).

A su vez, el valor bruto de producción en términos reales para toda la manufactura se incrementó notoriamente. Esta situación fue acompañada por una expansión del empleo industrial, que creció de 898.000 registrados en 2004 a 1,288 millones en 2013. Pero a partir de ese momento, la situación comenzó a modificarse en varios sectores. Si bien la crisis de 2009 no generó una recesión industrial de la magnitud de la de Estados Unidos, para 2013 los problemas estructurales de la economía argentina comenzaron a salir a la superficie. A nivel de la industria manufacturera, inconvenientes como la dificultad para importar insumos por la crisis de balanza de pagos, el agotamiento del modelo basado en el consumo interno, la recesión en Brasil y la debacle de Venezuela (dos de los mercados de exportación más importantes de la Argentina), erosionaron la actividad en varias ramas. De esta manera, la capacidad utilizada comenzó a caer y descendió en los últimos dos años a niveles de 2003. Edición, productos del caucho y de plástico, y automotriz fueron las más afectadas, 
si bien el movimiento fue general en varios sectores. Se experimentó una caída del valor bruto de producción, que coincidió con un descenso de la producción física en actividades como los lácteos, bebidas, tabaco, papel, refinación, artículos del hogar, vehículos y metálicas básicas (figuras 9, 9b y 9c).

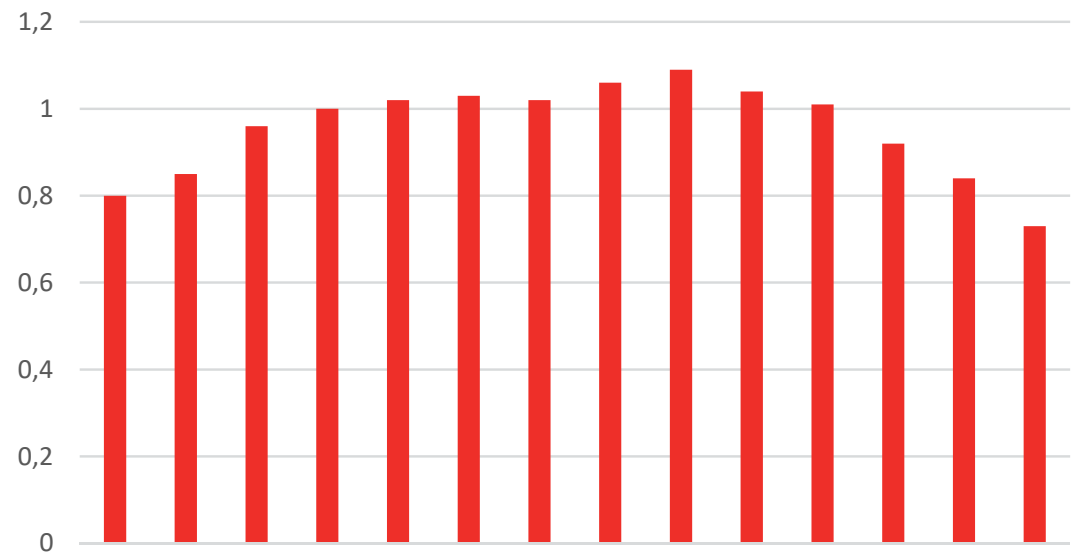

20042005200620072008200920102011201220132014201520162017

Figura 9. Producción física promedio en la industria láctea, 2004-2017 (2007 = 1)

Fuente: elaboración propia con base en Estadística de productos industriales del Indec (2017).

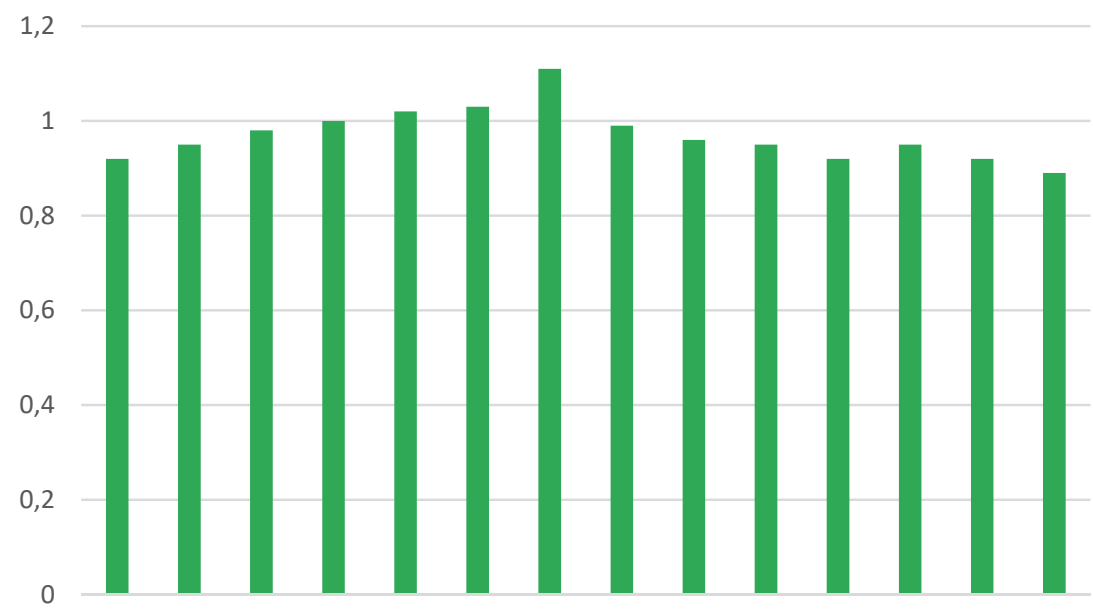

20042005200620072008200920102011201220132014201520162017

Figura 9b. Producción física promedio en la industria papelera, 2004-2017 (2007 = 1)

Fuente: elaboración propia con base en Estadística de productos industriales del Indec (2017). 


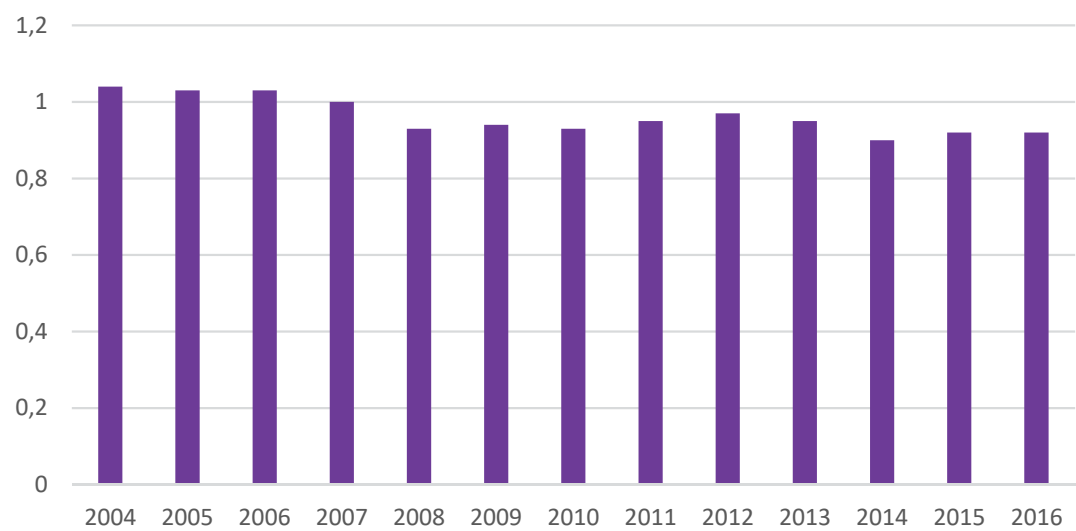

Figura 9c. Producción física promedio en la industria química básica, 2004-2016 (2007 = 1)

Fuente: elaboración propia con base en Estadística de productos industriales del Indec (2017).

Si bien ciertas actividades incrementaron su producción (ciertos renglones de la industria electrónica, como los celulares), en ramas claves se estancó. En algunas de estas ramas el incremento de productividad se detuvo luego del techo de 2011-2013, mientras que otras arrastraron límites previos. Ese movimiento no fue acompañado de una disminución en la plantilla de personal empleado en la misma magnitud. Por el contrario, la misma se incrementó, si bien con leves caídas en algunos años (2009 y de 2014 a 2017). De 2013 a 2017, el empleo manufacturero retrocedió un 4 \%. Pero la capacidad instalada lo hizo en más del $10 \%$, y el valor de producción el $6 \%$ (figura 10).

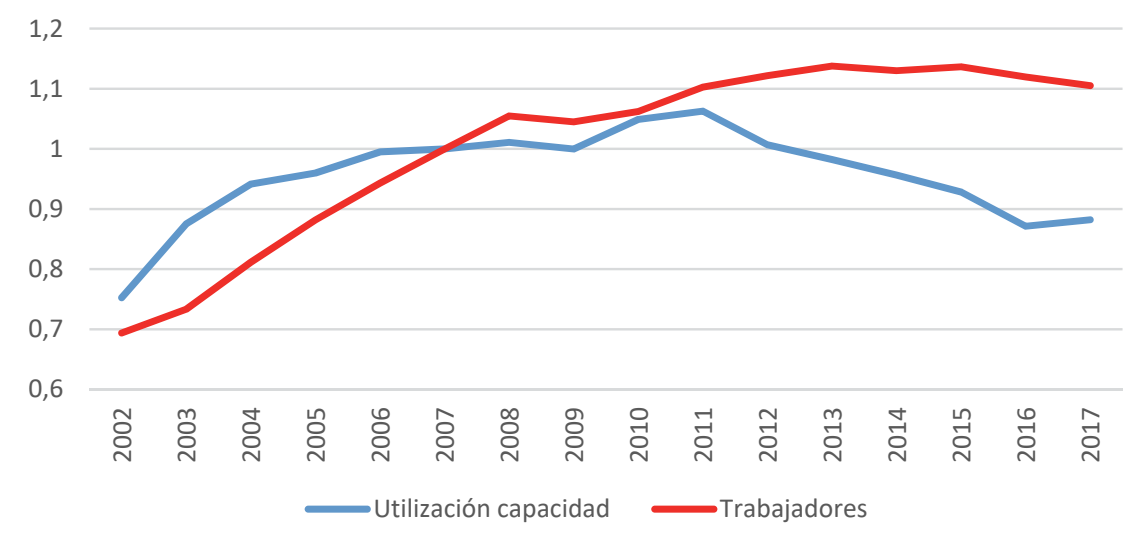

Figura 10. Evolución de capacidad instalada utilizada y de trabajadores en la industria manufacturera, 2002-2017 (base $2004=1$ )

Fuente: elaboración propia con base en Utilización de la capacidad instalada en la industria, Indec (varios años) y Boletín de Empleo Registrado. Serie anual, Observatorio de Empleo y Dinámica Empresarial (2017). 
Esto contrasta con la situación de otros países, como los Estados Unidos. En este país, la plantilla en los sectores principales de la industria cayó de casi doce millones de ocupados a diez millones entre 2004 y 2017 (una caída del 15 \%). Ciertamente, la crisis de 2009 actuó como punto de inflexión: la capacidad utilizada cayó 10 puntos (de casi $90 \%$ a 80 \%) y la ocupación se contrajo de 11,1 millones a 9,8 millones de trabajadores. Lo relevante del asunto es que luego la capacidad utilizada se incrementó (sin interrupciones hasta 2014-2015), pero el empleo fabril se mantuvo casi constante (figuras 11 y 12). Esto quiere decir que, debido a la flexibilidad del mercado laboral, la crisis sirvió como forma de ajustar la plantilla a la nueva situación. En el país del norte, algunos sectores perdieron entre 18 y $34 \%$ de sus ocupados en el lapso 2004-2017: como vehículos (18\%), metales básicos (20\%), computadoras y electrónicos (22\%), madera o papel (25\%), edición (34\%).

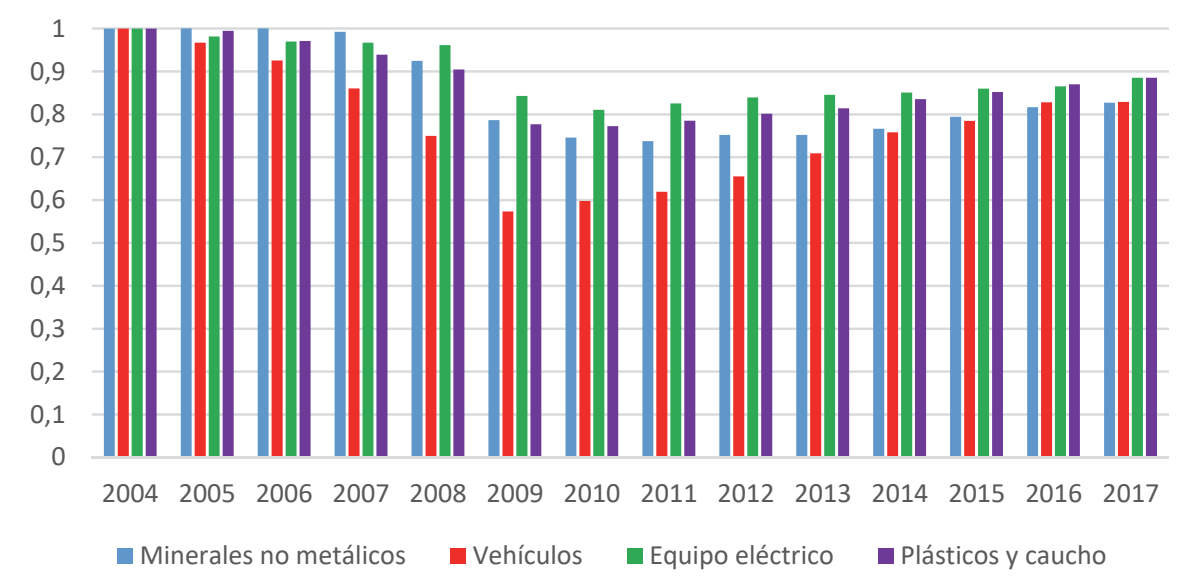

Figura 11. Evolución de ocupados en sectores industriales seleccionados en los Estados Unidos, 2004-2017 (base $2004=1$ )

Fuente: elaboración propia con base en información de Employment Statistics Survey, U.S. Bureau of Labor Statistics (varios años).

Como se vio en las figuras 10 y 11, en los Estados Unidos la crisis de 2009 "depuró" la plantilla de ocupados en la actividad manufacturera, cuando se desplazaron casi 1,2 millones de puestos ante una caída de más de nueve puntos en la capacidad utilizada. Luego de ello la actividad se recuperó de forma progresiva. La ocupación se mantuvo estable, con un crecimiento de apenas doscientos mil puestos en ocho años. Por el contrario, en la Argentina ese fenómeno no ocurrió. El empleo se sostuvo incluso iniciada una nueva recesión. Esa contradicción se manifestó en el incremento de las suspensiones desde la segunda mitad del mandato final de Cristina Fernández y en la multiplicación de los planes Repro, subsidio estatal para pagar parte de los salarios de empresas privadas. En términos reales, los beneficiarios pasaron de 471.000 en 2012 
a 756.500 en 2015 (de casi 40.000 a 63.000 por mes), y el monto (en pesos de enero de 2017) se incrementó de 1.163 millones a 1.811 millones.

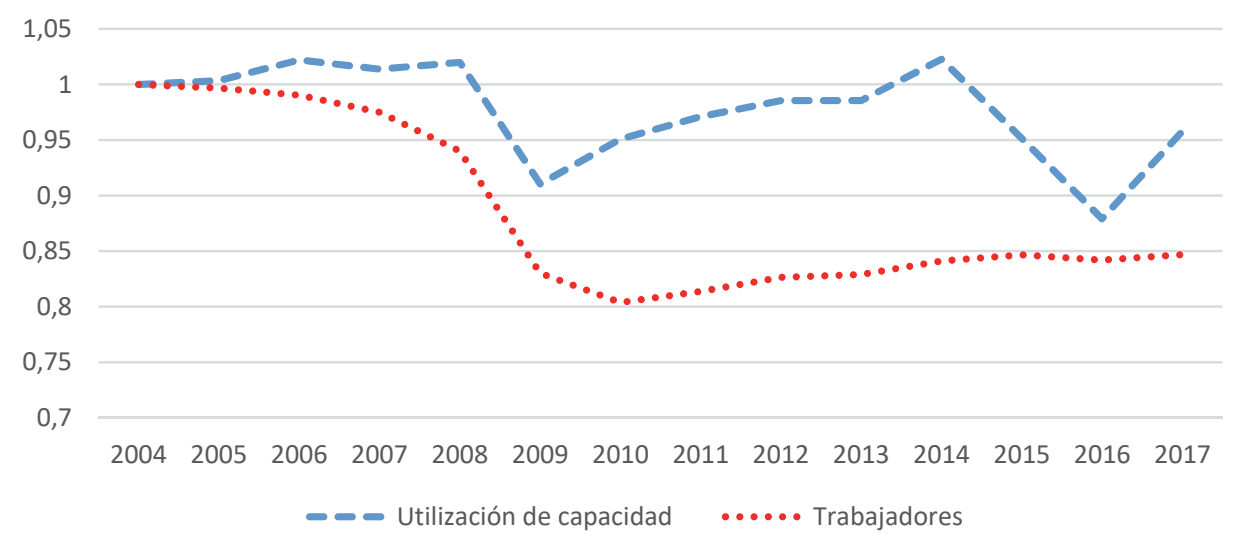

Figura 12. Evolución de capacidad utilizada y trabajadores ocupados en la industria manufacturera de los Estados Unidos, 2004-2017 (base 2004 = 1)

Fuente: elaboración propia con base en información de Employment Statistics Survey, U.S. Bureau of Labor Statistics (varios años) y de Industrial Production and Capacity Utilization, Board of Governors of the Federal Reserve (2018).

\section{LA ESTRATEGIA DEL CAPITAL}

Lo expuesto previamente indica, a nuestro entender, que en una estructura laboral relativamente rígida como la Argentina, en la cual los costos de contratación y de despido son elevados y donde el Estado, por condicionamientos políticos, no puede dejar que el desempleo aumente de forma brutal, la crisis de acumulación genera un problema adicional a los empresarios. Si bien la concentración de capital se consolidó en los últimos años (unidades más grandes con participación de mercado creciente), los capitalistas no pueden aprovechar al máximo las potenciales ganancias por aumento de escalas productivas debido a la dificultad para adecuar la plantilla, cuyo volumen es superior al que podría ser utilizado con mejores condiciones contractuales para el patrón, como ocurre en los Estados Unidos. El estancamiento del producto por ocupado es indicio de ello. En consecuencia, en plena crisis de acumulación y ante la necesidad de regenerar condiciones, es moneda corriente observar en diarios y distintas publicaciones a diversos representantes de la burguesía argentina reclamar una reducción del costo laboral, entre otros pedidos.

Hasta el momento, aunque el empleo privado descendió, la crisis no se reflejó en una masa de despidos abiertos y en la disparada de la desocupación como en los ochenta y noventa. Lo que evidencia esta situación, en parte, es la acumulación de una masa de población sobrante para el capital oculta en las fábricas que aún no 
pudo ser sincerada. Lo que reclama el capital, entonces, es bajar el costo contractual, entendido como costo de contratar, mantener como activo y despedir a un trabajador. Con la reforma laboral, el Gobierno y la burguesía buscarían desandar el camino para reducir ese ítem y alinear la plantilla a la necesidad del ciclo industrial y permitir a la burguesía realizar la ganancia producto del incremento de escala. El capital se ahorraría ese costo, que se trasladaría a lo que obtiene como ganancia del ciclo de producción y consumo. Por ello señalamos que esta medida se presentó como una pata del "cambio" junto con la previsional y la impositiva que buscan destrabar las condiciones para la acumulación de capital en Argentina.

\section{CONCLUSIONES}

En este trabajo recorrimos la historia reciente de las reformas laborales en Argentina. Observamos cómo las mismas reflejan la pugna y el avance del capital sobre el trabajo. El primero busca, por intermedio de la modificación de regulaciones existentes, facilitar un uso más flexible de la fuerza de trabajo, bien sea por la vía de modificar condiciones (polivalencia, rotación, categorías, tiempos de descanso, etc.) o por la de abaratar la mano de obra (atando salario a productividad, reduciendo el cálculo de indemnizaciones o dificultando el acceso a la justicia laboral, entre otras). Como señalaron diversos autores, esta disputa no es algo propio de lo que se denominó como "neoliberalismo". Por caso en la Argentina, los primeros avances consistentes del capital sobre el trabajo se retrotraen al segundo gobierno de Perón, coincidente con la crisis de acumulación que se abre a comienzos de los cincuenta. En ese marco, la propuesta actual del macrismo es otra vuelta de tuerca en este largo proceso de degradación de las condiciones de los trabajadores en el país.

Por ello, en segundo término, analizamos los condicionantes económicos estructurales que impulsan al Gobierno a lanzar el proyecto. Básicamente, lo que se observa es que el mercado laboral argentino es relativamente rígido. Esto quiere decir que los costos de contratación y despido son elevados en términos regionales e internacionales. Así, cuando el ciclo industrial entra en receso, la plantilla de ocupados no se adapta a la caída de la capacidad utilizada. Ello genera costos adicionales a los empresarios, y cuando el ciclo vuelve a ascender se dificulta absorber la ganancia debido al incremento de escala y productividad. Por ello, la burguesía presiona para la flexibilización de estas condiciones y busca una configuración más parecida a otros competidores regionales con costos laborales más baratos (Brasil o México) o al caso norteamericano, donde el mercado de trabajo es mucho más fluido (sobre todo, como observamos, a partir de la crisis de 2008-2009). En este sentido, la reforma es una medida industrialista. Está motorizada por la burguesía nacional, entendiendo por tal la que opera en el país, sea de capital local o extranjero. Así funciona el capital, compitiendo por bajar sus costos, y el laboral es uno de ellos. 


\section{REFERENCIAS}

Altimir, O. y Beccaria, L. (2000). El mercado de trabajo bajo el nuevo régimen económico en Argentina. En D. Heymann y B. Kosacoff (eds.), La Argentina de los noventa. Desempeño económico en un contexto de reformas (pp. 331-423). Eudeba.

Asociación de Fábricas de Automotores, Adefa (2018). Anuario. Datos básicos. http://www.adefa.org.ar/ upload/anuarios/anuario2018/3.pdf

Banco Mundial (1995). Informe sobre el desarrollo mundial. El mundo del trabajo en una economía integrada.

Board of Governors of the Federal Reserve (2018). G.17. Industrial Production and Capacity Utilization. https://www.federalreserve.gov/releases/G17/default.htm

Candal, M. (2014). Los 40 años de la ley 20.744. Apogeo, decadencia y reconstrucción. Revista Derecho del Trabajo, 3(9), 55-75. https://cutt.ly/UfYdibY

De Diego, J. (2017). Reforma Laboral. De Diego y Asociados.

De la Garza Toledo, E. (2000). La flexibilidad del trabajo en América Latina. En E. De la Garza Toledo (ed.), Tratado Latinoamericanos de Sociología del Trabajo (pp. 148-178). Editorial Siglo XXI.

De Palma, A. (1972). La organización capitalista del trabajo en El Capital de Marx. En A. De Palma, R. Panzieri, M. Salvati, B. Beccalli, A. Lettieri, y A. Gorz (comps.), La división capitalista del trabajo. Pasado y Presente.

Do Rosario, J. (201, 731 de octubre). Los empresarios festejan el plan de reformas de Macri y se suman a las mesas de diálogo. Infobae. https://www.infobae.com/economia/2017/10/31/los-empresariosfestejan-el-plan-de-reformas-de-macri-y-se-suman-a-las-mesas-de-dialogo/

Ferreres, O. (2010). Dos siglos de economía argentina, 1810-2004. Historia argentina en cifras. Editorial El Ateneo.

Harari, I. (2019). Los obreros de la construcción y el largo camino de la degradación. En XVII Jornadas Interescuelas/Departamentos de Historia, Catamarca, Argentina.

Honorable Congreso de la Nación Argentina (1933, 26 de septiembre). Ley 11.729. Código de Comercio. Publicada en el Boletín Oficial nº 12086 (25/09/1934). http://servicios.infoleg.gob.ar/infolegInternet/ verNorma.do?id $=42760$.

Honorable Congreso de la Nación Argentina (1974, 20 de septiembre). Ley 20.744. Ley de Contrato de Trabajo. Publicada en el Boletín Oficial n² 23.003 (27/09/1974). http://servicios.infoleg.gob.ar/ infolegInternet/anexos/25000-29999/25552/norma.htm

Honorable Congreso de la Nación Argentina (1987, 25 de marzo). Ley 23.472. Créditos laborales - Creación de fondo de garantía. Publicada en el Boletín Oficial n² 26.113 (25/03/1987). http://servicios.infoleg. gob.ar/infolegInternet/anexos/20000-24999/21976/norma.htm

Honorable Congreso de la Nación Argentina (1989, 1 de septiembre). Ley 23.697. Ley de Emergencia Económica. Estado de emergencia. Publicada en el Boletín Oficial n² 26.725 (25/09/1989). http://servicios. infoleg.gob.ar/infolegInternet/anexos/0 4999/15/norma.htm

Honorable Congreso de la Nación Argentina (1991, 13 de noviembre). Ley 24.013. Ley de empleo. Protección del trabajo. Publicada en el Boletín Oficial n² 27.286 (17/12/1991). http://servicios.infoleg.gob.ar/ infolegInternet/anexos/0-4999/412/norma.htm 
Honorable Congreso de la Nación Argentina (1995, 15 de marzo). Ley 24.465. Régimen de Contrato de Trabajo. Modificación. Publicada en el Boletín Oficial n² 28.112 (28/03/1995). http://servicios.infoleg. gob.ar/infolegInternet/anexos/15000-19999/15931/norma.htm

Honorable Congreso de la Nación Argentina (1995, 28 de marzo). Ley 24.467. Marco regulatorio de la Pequeña y Mediana Empresa. Publicada en el Boletín Oficial n 28.112 (28/03/1995). http://servicios. infoleg.gob.ar/infolegInternet/anexos/15000-19999/15932/norma.htm

Honorable Congreso de la Nación Argentina (1998, 2 de septiembre). Ley 25.013. Reforma Laboral. Modificaciones de Leyes 24.013, 24.465 y 24.467. Publicada en el Boletín Oficial n² 28.987 (24/09/1998). http://servicios.infoleg.gob.ar/infolegInternet/anexos/50000-54999/53159/norma.htm

Honorable Congreso de la Nación Argentina (2000, 11 de mayo). Ley 25.250. Reforma Laboral - Aprobación. Publicada en el Boletín Oficial n 29.411 (2/06/2000). http://servicios.infoleg.gob.ar/infolegInternet/ anexos/60000-64999/63208/norma.htm

Honorable Congreso de la Nación Argentina (2004, 2 de marzo). Ley 25.877. Régimen Laboral. Ordenamiento del régimen laboral. Derogación ley nro. 25.250. Publicada en el Boletín Oficial nº 30.364 (19/03/2004). http://servicios.infoleg.gob.ar/infolegInternet/anexos/90000-94999/93595/norma.htm

Honorable Congreso de la Nación Argentina (2014, 21 de mayo). Ley 26.940. Promoción del Trabajo registrado y prevención del fraude laboral. Registro público de Empleadores con sanciones laborales. Publicada en el Boletín Oficial n 32.896 (2/06/2014). http://servicios.infoleg.gob.ar/infolegInternet/ anexos/230000-234999/230592/norma.htm

Instituto Nacional de Estadísticas y Censos - Indec (1974-2016). Encuesta Permanente de Hogares. INDEC. https://www.indec.gob.ar/indec/web/Institucional-Indec-InformesTecnicos-152

Instituto Nacional de Estadísticas y Censos - Indec (varios años). Utilización de la capacidad instalada en la industria. Serie "Industria Manufacturera", ISSN 2545-6636. Informes recientes y serie histórica. https://www.indec.gob.ar/indec/web/Institucional-Indec-InformesTecnicos-15

Instituto Nacional de Estadísticas y Censos - Indec (varios años). Estadísticas de Productos Industriales. ISSN 2545-7152. https://www.indec.gob.ar/indec/web/Nivel4-Tema-3-6-18

Instituto Nacional de Estadísticas y Censos - Indec (2020). "Series por sector de actividad económica: valor bruto de producción y valor agregado bruto. Años 2004-2020 por trimestre", Agregados Macroeconómicos, Cuentas Nacionales. https://www.indec.gob.ar/ftp/cuadros/economia/sh_VBP_ VAB_12_20.xls

James, D. (1981). Racionalización y respuesta de la clase obrera contexto y limitaciones de la actividad gremial en la Argentina. Desarrollo económico, 21(83), 321-349. https://historiasocialargentinaunlp. com.ar/wp-content/uploads/2018/04/daniel-james.pdf

Kabat, M., Harari, I., Egan, J., Fernández, R., Cominiello, S., Muñoz, R. y Murmis, E. (2014). Avances y retrocesos de la flexibilidad laboral en la Argentina. Aportes para una comparación de las trayectorias históricas de distintas ramas de actividad. Mundos do Trabalho, 6(12), 273-297. https:// doi.org/10.5007/1984-9222.2014v6n12p273

Katz, C. (2017). El proyecto neoliberal en Argentina. Mundo Silgo, 12(41), 31-36. https://www. mundosigloxxi.ipn.mx/pdf/v12/41/04.pdf

Levaggi, A. (2006). Historia del derecho argentino del trabajo (1800-2000). Iushistoria (3), 1-101. https:// p3.usal.edu.ar/index.php/iushistoria/article/view/1617/2050 
Marticorena, C. (2010). Contenidos de la negociación colectiva durante la década de 1990 y la posconvertibilidad en actividades seleccionadas de la industria manufacturera. Estudios del Trabajo (39/40), 59-87. https://www.researchgate.net/publication/270818482_Contenidos_de_la_ negociacion_colectiva_durante_la_decada_de_1990_y_la_posconvertibilidad_en_actividades_ seleccionadas_de_la_industria_manufacturera

Montes Cato, J. y Ventrici, P. (2017). Pérdida de derechos laborales en la restauración neoliberal Argentina. Revista de Políticas Públicas, 21(2), 661-680. http://dx.doi.org/10.18764/2178-2865. v2 $\ln 2 \mathrm{p} 661-680$

Observatorio de Empleo y Dinámica Empresarial, Ministerio de Trabajo, Empleo y Seguridad Social (2017). Boletín de empleo registrado. Serie Anual - Año 2017. http://www.trabajo.gob.ar/downloads/ estadisticas/oede/nacional_serie_empleo_anual.xlsx

OECD (2019). Argentina. Economic Surveys.

Palomino, H. y Trajtemberg, D. (2006). Una nueva dinámica de las relaciones laborales y la negociación colectiva en la Argentina. Revista de Trabajo (3), 47-68. http://www.trabajo.gob.ar/downloads/ estadisticas/2006n03_revistaDeTrabajo.pdf

Poder Ejecutivo Nacional (1967, 2 de mayo). Decreto-Ley [gobierno de facto]: Industria y Construcción. Régimen General. Publicado en el Boletín Oficial n² 21.181 (2/05/1967). http://servicios.infoleg.gob. ar/infolegInternet/verNorma.do\%3Bjsessionid =3BFBFF100CD 186E32E7E754E7CC2E7FC?id=96 296\#: : :text=Resumen\%3A,LA\%20INDUSTRIA\%20DE\%20LA\%20CONTRUCCION.

Poder Ejecutivo Nacional (1976, 21 de mayo). Decreto [gobierno de factol: Contrato de trabajo. Ley 20.744. Texto ordenado. Publicado en el Boletín Oficial n² 23.410 (21/05/1976). http://servicios.infoleg.gob. ar/infolegInternet/anexos/225000-229999/229909/norma.htm

Poder Ejecutivo Nacional (1979, 15 de noviembre). Decreto [gobierno de facto]: Trabajo. Decreto-Ley $n^{\circ}$ 16.115/33 - Modificación. Publicado en el Boletín Oficial n² 24.297 (21/11/1979). http://servicios. infoleg.gob.ar/infolegInternet/anexos/185000-189999/185859/norma.htm

Poder Ejecutivo Nacional (1980, 17 de julio). Ley Igobierno de factol: Industria de la Construcción. Nuevo Régimen. Publicado en el Boletín Oficial nº 24.460 (17/07/1980). http://servicios.infoleg.gob.ar/ infolegInternet/anexos/25000-29999/27238/norma.htm

Poder Ejecutivo Nacional (1980, 31 de octubre). Ley [gobierno de factol: Contrato de trabajo. Modificación. Publicado en el Boletín Oficial n 24.540 (7/11/1980). http://servicios.infoleg.gob.ar/infolegInternet/ anexos/75000-79999/77207/norma.htm

Sanz Cerbino, G., Primucci, M., Toro Tesini, M., Fennema, M. (2018). "La hegemonía desarrollista. Programa e influencia política de la gran burguesía industrial argentina, 1976-2018". XI Jornadas de Economía Crítica, Santa Fe, Argentina.

Sartelli, E. (2001). Para comer una hamburguesa. El estudio de los procesos de trabajo, el debate Braverman y el 'fast food' en Argentina. Razón y Revolución (7). https://revistaryr.org.ar/index.php/ RyR/article/view/336

Schwab, K. (2017). The Global Competitiveness Report 2017-2018. World Economic Forum.

U.S. Bureau of Labor Statistics (varios años). Foreign Labor Statistics database. https://data.bls.gov/ PDQWeb/in

U.S. Bureau of Labor Statistics (varios años). Employment Statistics Survey. https://data.bls.gov/PDQWeb/ce 
254 lanina Harari y Damián Bil

World Bank (2017). Doing Business database. https://databank.worldbank.org/source/doing-business

Zicari, J. (2016). Las coaliciones neoliberales en la Argentina: los casos de la Alianza y Cambiemos. Realidad Económica, (307), 6-36. https://cutt.ly/7fYiSRb 